\title{
KAJIAN BIBLIKA TENTANG MENGHAKIMI DALAM JEMAAT BERDASARKAN 1 KORINTUS 5:12-13
}

\author{
Septiandriani, Christopher James Luthy
}

\begin{abstract}
Abstrak
Menghakimi dalam jemaat seringkali tidak bisa diimplikasikan sepenuhnya karena berbagai alasan. Jemaat seringkali takut terhadap hukum kasih jika menerapkan penghakiman dalam jemaat. Oleh kerena itu, tulisan ini ditulis dengan tujuan menemukan makna dari menghakimi dalam jemaat dan implementasinya di dalam gereja. Adapun metode penelitian yang digunakan dalam tulisan ini adalah metode penelitian kualitatif dengan menggunakan prinsip-prinsip hermeneutik. Tahapan dalam penelitian ini adalah dengan menganalisa tentang pandangan umum kitab antara lain latar belakang kitab, penulis kitab, penerima kitab, waktu dan tempat penulisan kitab, tema-tema besar kitab, tujuan penulisan kitab dan garis-garis besar kitab serta menganalisa makna dari menghakimi dalam jemaat berdasarkan 1 Korintus 5:12-13. Berdasarkan dari hasil penelitian maka dapat disimpulkan bahwa menghakimi dalam jemaat penting dilakukan dalam gereja, bukan dengan tujuan mencari kesalahan orang lain dan tidak menerapkan kasih, melainkan dilakukan untuk menjaga kekudusan jemaat. Orang-orang yang tidak mau hidup kudus lebih baik dikeluarkan dari jemaat sebelum membawa pengaruh buruk pada jemaat.
\end{abstract}

Kata-Kata Kunci: Allah, Menghakimi, Kasih, Jemaat Korintus, Usirlah, Pengucilan, dan Kekudusan

\section{Pendahuluan}

\section{Latar Belakang Masalah}

Jika melihat masalah yang terjadi dalam gereja, banyaknya anggota jemaat yang jatuh dan gereja bertanggung jawab untuk menghakimi dan membersihkan diri dari dosa, penulis melihat timbul masalah implikasi dalam hal "menghakimi". Gereja sering sangat segan untuk menghakimi anggota jemaatnya karena hal-hal tertentu. Penyebabnya adalah karena kurangnya pemahaman pentingnya menghakimi dalam jemaat diterapkan.

Gereja seringkali mengalami kesulitan dan bingung ketika harus menentukan sikap terhadap jemaat yang berbuat dosa dan memilih sikap ekstrim yaitu membiarakan seseorang jatuh ke dalam dosa karena takut menegur dan membuat mereka tersinggung. Sikap yang lebih parah adalah ketika gereja sangat membenci dosa, sehingga juga membenci orang yang berbuat dosa. Banyak gereja yang lalai menerapkan disiplin dalam gereja masa kini, karena takut dianggap bertentangan dengan "kasih Allah" dan dapat menjadi penyebab perpecahan dan perselisihan dalam jemaat. Banyak orang yang memandang disiplin gereja itu seperti sebuah 
kutukan dari pada melihatnya sebagai cinta kasih yang dapat menjaga dan memulihkan persekutuan umat Tuhan. ${ }^{1}$

Menghakimi dalam Perjajian Baru adalah sesuatu yang bersifat melarang. Ajaranajaran dalam Perjanjian Baru memberi peringatan untuk tidak menghakimi orang lain. Dalam khotbah-Nya di bukit menegaskan untuk tidak menghakimi orang lain, karena setiap orang yang menghakimi akan dihakimi menurut ukuran penghakimannya terhadap orang lain (Mat. 7:1-2 dan Luk. 6:37). Hal ini menunjukkan betapa tidak baiknya seorang jika menghakimi orang lain.

Ada alasan yang kuat mengapa menghakimi tidak diperbolehkan karena kehidupan orang Yahudi dalam zaman Perjanjian Baru hidup saling mengkritik kehidupan orang lain tanpa melihat kesalahan yang terdapat pada dirinya sendiri. Yesus memberikan ajaran ini, agar setiap orang sadar bahwa cara mereka memperlakukan orang lain akan sama dengan cara Tuhan dan orang lain menghakimi mereka.

Dilarang menghakimi bukan berarti tidak membenarkan tindakan pengoreksian. ${ }^{2}$ Sebagai orang yang hidup dalam satu persekutuan orang percaya harus saling memperhatikan dan saling menegur. Jemaat bertanggung jawab untuk menghakimi orangorang dalam jemaat yang melakukan dosa, seperti yang dijelaskan Paulus dalam surat Efesus bahwa segala sesuatu telah diletakkan-Nya di bawa kaki Kristus dan Dia telah diberikan-Nya kepada jemaat (Ef. 1:22).

Orang Kristen disebut juga orang kudus, yang sudah bisa membedakan antara baik dan buruknya suatu tindakan, antara kekudusan dan dosa serta menjauhkan diri dari kehidupan yang tidak memuliakan Tuhan. ${ }^{3}$ Orang kudus harus hidup kudus dan tidak bergaul dengan orang-orang yang tidak menjaga kekudusan. Hal ini bukan menujukkan kesombongan, tetapi memang jemaat Kristus adalah jemaat yang kudus. Orang Kristen mengimani bahwa hanya Tuhan yang kudus. ${ }^{4}$ Orang yang percaya kepada-Nya akan dikuduskan bagi-Nya melalui pengorbanan Yesus Kristus di kayu Salib karena tanpa hidup kudus, manusia tidak mungkin memiliki persekutuan dengan Allah yang kudus. ${ }^{5}$ Hidup kudus berarti harus menjauhi dosa karena Allah yang dipercaya kudus dari dosa dan juga dituntut untuk hidup sesuai hukum yang diberikan oleh Tuhan.

Melihat bagaimana gereja sekarang hidup dalam dunia yang semakin maju dan akan semakin kuat memicu orang untuk berbuat dosa. Perkembngan teknologi dan pengetahuan manusia terus mendorong melakukan hal buruk yang tidak sesuai dengan karakter seorang pengikut Kristus. Saling mengingatkan satu dengan yang lain berarti setiap anggota jemaat siap untuk menegur, mengingatkan saudaranya yang jatuh ke dalam dosa. Pemimpin-pemimpin gereja bertanggung jawab melaksanakan pelayanan pastoral dan menghakimi setiap hidup dan tingkah laku jemaat yang melanggar hukum gereja guna pertumbuhan ronani yang baik. Gereja tidak boleh lalai dan bermasa bodoh terhadap

\footnotetext{
${ }^{1}$ Yohanis Luni Tumanan, "Disiplin Gereja Berdasaarkan Injil Matius 18:15-17 dan Implementasinya Dalam Gereja Masa Kini,” Jurnal Jaffray 15, no. 1 (April 2017), 32, diakses 24 Maret 2019, https://media.neliti.com/media/publications/102849-disiplin-gereja-berdasarkan-injil-matius-5c167cf4.pdf

${ }^{2}$ Dianne Bergant OFM CSA \& Robert J. Karris, Tafsir Alkitab Perjanjian Baru (Yogyakarta: Kanisius, 2010), 46. Februari 2019,

${ }^{3}$ V. C. Pfitzner, Kesatuan Dalam Kepelbagaian (Jakarta: BPK Gunung Mulia, 2006), 88, diakses 25 https://books.google.com/books/about/Kesatuan_Dalam_Kepelbagaian.html?hl=id\&id=o0xaKe1i80UC.

${ }^{4}$ Harun Hadiwijono, Iman Kristen, (Jakarta: BPK Gunung Mulia, 2010), 91.

${ }^{5}$ Friliany Putiray, "Studi Etis Kristiani terhadap Pemahaman Pasangan Nikah Married by Accident di Jemaat GPM Galala - Hative Kecil tentang Kekudusan Pernikahan" (Skipsi, S.Si-Teo, Universitas Kristen Satya Wacana, 2014), 1, diakses 25 Maret 2019, http://repository.uksw.edu/handle/123456789/12258.
} 
jemaatnya. Penegasan tentang pendisiplinan gereja untuk menjaga kekudusan dalam jemaat kejahatan dan dosa yang menodai jemaat Tuhan, harus dihukum oleh gereja sehingga sang pelaku boleh bertobat dan diselamatkan. ${ }^{6}$

Jika melihat secara singkat dari kehidupan orang Korintus, di antara mereka ada percabulan dengan orang-orang yang tidak mengenal Tuhan. Ada di antara mereka yang mengaku jemaat, namun kehidupannya jauh dari pada gaya hidup orang Kristen. Penulis menggambarkan kehidupan percabulan mereka itu sangat begitu rupa, seperti "tidak terdapat sekalipun di antara bangsa-bangsa yang tidak menganal Tuhan (1 Kor. 5:1)." Pernyataan penulis ini, menggambarkan begitu parahnya dosa percabulan yang terjadi di Korintus yang mengaku sebagai orang percaya.

Meskipun hidup dalam keadaan seperti ini mereka masih tetap hidup dalam kesombongan. Mereka seharusnya menjauhkan orang-orang seperti itu dari dalam kelompok mereka. Namun, yang mereka lakukan malah bermasa bodoh dan tidak peduli terhadap hal itu. Lebih dari pada itu, penulis menggambarkan mereka seperti adonan yang telah dicampur sedikit ragi dan terpengaruh oleh ragi itu (1 Kor. 5:6-8). Penulis mengajak mereka untuk hidup bukan dengan ragi yang lama, melainkan dengan ragi yang baru.

Ada beberapa orang yang mengaku sebagai bagian dari jemaat namun tetap hidup di dalam dosa. Mereka terus hidup dengan ragi yang lama dan tidak menggunakan ragi yang baru. Gaya hidup yang seperti inilah yang menjadi alasan penulis menegur mereka. seharusnya jemaat yang telah menerima Kristus hidup sesuai dengan ajaran Kristus dan meninggalkan kehidupan lama. Lebih dari pada itu, mereka dihimbau untuk tidak bergaul dengan orang-orang yang tidak mengenal Allah dan menegur jemaat dengan jelas agar orang itu mereka serahkan dalam nama Tuhan Yesus kepada iblis, sehingga tubuhnya dibinasakan, agar roh orang tersebut diselamatkan pada hari Tuhan (1 Kor 5:5). ${ }^{7}$ Melihat pada ayat 13 Paulus kembali menekankan bahwa penghakiman untuk orang yang berada di luar jemaat akan dihakimi oleh Allah.

Jika diperhatikan kembali, penulis berpikir bahwa maksud Paulus di sini adalah orang yang berada di luar jemaat bukanlah urusan orang yang berada dalam jemaat. Mereka yang berada di luar jemaat adalah urusan Allah pada hari penghakiman. Yang menjadi tanggung jawab gereja adalah anggota jemaatnya sendiri.

Melihat kembali ajaran untuk tidak menghakimi sesama dalam sebagian Besar Perjanjian Baru, Pernyataan Paulus dalam ayat 12 dan 13 yakni tentang wewenang menghakimi di dalam jemaat ini menimbulkan pertanyaan bagi gereja tentang bagaimana menghakimi dalam jemaat dengan baik dan benar tanpa mengabaikan ajaran kasih dan penekanan Perjanjian Baru tentang larangan menghakimi. Menghakimi dalam jemaat penting dilakukan jika melihat keadaan jemaat di Korintus dan juga keadaan dunia saat ini. Penulis memikirkan tentang apa yang dimaksud dengan penghakiman dalam jemaat dan bagaimana mengimplikasikannya dalam kehidupan sehari-hari selaku warga jemaat. Tulisan ini akan menggali tentang alasan penghakiman dilakukan di dalam jemaat.

Inilah yang menjadi pertanyaan penulis sehingga penulis mengambil kesimpulan untuk menulis skripsi ini dengan judul KAJIAN BIBLIKA TENTANG MENGHAKIMI DALAM JEMAAT BERDASARKAN 1 KORINTUS 5:12-13.

\section{Pokok Masalah}

Dengan melihat latar belakang masalah di atas, maka yang menjadi pokok masalah dalam penulisan ini adalah:

\footnotetext{
${ }^{6}$ Merrill C. Tenny, Survey Perjanjian Baru (Malang: Gandum Mas, 2013), 368.

${ }^{7}$ Adina Chapman, Pengantar Perjanjian Baru (Bandung: Kalam Hidup, 2014), 65.
} 
Pertama, apa yang dimaksudkan dengan menghakimi dalam jemaat berdasarkan 1 Korintus 5: 12-13?

K edua, bagaimana mengimplikasikannya dalam kehidupan berjemaat masa kini?

\section{Tujuan Penelitian}

Berdasarkan pokok masalah di atas, maka tujuan penulisan yang ingin dicapai dalam skripsi ini adalah:

Pertama, mengetahui makna yang dimaksud Paulus tentang penghakiman dalam jemaat berdasarkan 1 Korintus 5:12-13.

Kedua, mengetahui bagaimana implikasi penghakiman dalam jemaat berdasarkan 1 Korintus 5: 12-13.

\section{Manfaat Penelitian}

Adapun manfaat penulisan skripsi ini adalah sebagai berikut:

Pertama, mengembangkan ilmu dan wawasan penulis dalam hal menulis dan mengeksegesis Alkitab.

Kedua, skripsi ini menjadi bahan bacaan yang dapat menambah wawasan bagi penulis dan pembaca utamanya mengenai hal menghakimi dalam jemaat.

Ketiga, untuk memenuhi salah satu syarat akademik dalam mencapai gelar sarjana pada Sekolah Tinggi Filsafat Jaffray Makassar.

\section{Metode Penelitian}

Dalam penulisan skripsi ini, penulis menggunakan metode penelitian kualitatif ${ }^{8}$ dengan menggunakan prinsip-prinsip hermeneutik. Hermeneutik adalah cara mengartikan kitab suci. Menurut Zygmunt Baumant hermeneutik adalah upaya menjelaskan dan menelusuri pesan dan pengertian dasar dari sebuah tulisan. ${ }^{9}$

Hermeneutik dalam bahasa Yunani berarti menginterpretasi, menjelaskan atau menerjemahkan. Dalam pengertian sempit hermeneutik Alkitab hanya memusatkan perhatian pada Alkitab orang Kristen saja. Hermeneutik adalah suatu bagian teologi yang bersifat ilmia dan seni, yang memperhatikan hukum tertentu bahkan melibatkan diri penafsir sepenuhnya, dengan tujuan mencari maksud yang ingin disampaikan oleh penulis Alkitab. ${ }^{10}$

Untuk itu dalam penulisan skripsi ini, penulis akan mengikuti langkah-langkah hermeneutik. Oleh karena itu, penulis mengumpulkan referensi melalui literature, terhadap berbagai sumber yaitu Alkitab, kamus, tafsiran-tafsiran, buku-buku dan tulisan-tulisan online yang berhubungan tengan teks. Selain itu, akan disertakan juga ayat-ayat yang berhubungan dengan teks yang akan dibahas yang berhubungan dengan pembahasan dalam skripsi ini.

\section{Batasan Penelitian}

Menghakimi dalam Alkitab sangat banyak dibahas dan konteksnyapun berbedabeda. Oleh sebab itu dalam penulisan skripsi ini, untuk menghindari pembahasan yang terlalu jauh dan tidak sesuai dengan teks maka penulis membatasi penulisan ini dengan

\footnotetext{
${ }^{8}$ Frederik, 69; Anizah, 123; Rajo, 144.

${ }^{9}$ Syahrin Harahap, Metodologi Studi Tokoh \& Penulisan Biografi (Jakarta: Prenada Media, 2014),
} 50. Harahap mengutip, Zygment Bauman, Hermeneutic and Social Scince (New York: Calubia Univercity Press, 1978), 7.

${ }^{10}$ Hasan Sutanto, Hermeneutik:Prinsip dan Metode Penafsiran Alkitab (Malang: Seminari Alkitab Asia Tenggara, 1998), 2-3. 
berfokus pada menghakimi dalam jemaat berdasarkan kitab 1 Korintus 5:12-13 dan implikasinya dalam kehidupan masa kini. Adapun teks lain yang berkaitan dengan teks ini akan ditambahkan jika diperlukan.

\section{Sistematika Penelitian}

Adapun sistematika penulisan skripsi ini ditulis atas lima bab yang dikemukakan sebagai berikut:

Bab pertama, bab pendahuluan yang berisi latar belakang, pokok masalah, tujuan penulisan, manfaat penulisan, metode penelitian, batasan penulisan dan sistematika penulisan.

Bab kedua, merupakan bab yang membahas pandangan umum kitab 1 Korintus yaitu, latar belakang Kitab 1 Korintus, penulis Kitab 1 Korintus, penerima Kitab 1 Korintus, Waktu dan tempat penulisan kitab 1 Korintus, tema-tema besar kitab 1 Korintus, tujuan penulisan Kitab 1 Korintus dan garis-garis besar kitab 1 korintus.

Bab ketiga, membahas tentang menghakimi dalam jemaat berdasarkan kitab 1 Korintus 5:12-13.

Bab keempat, membahas implikasi tentang menghakimi dalam jemaat berdasarkan 1 Korintus 5:12-13.

Bab kelima, merupakan bab penutup yang terdiri dari kesimpulan dan saran.

\section{Kesimpulan}

Setelah pembahasan panjang tentang kajian biblika dari satu Korintus ini, maka penulis mencoba menarik beberapa kesimpualan, sebagai hasil pembahsan dalam tulisan ini.

Pertama, surat satu Korintus adalah merupakan salah satu bukti Rasul Paulus menerapkan hal menghakimi di dalam jemaat. Paulus menulis surat dan menyatakan berbagai kesalahan dan dosa-dosa yang terjadi di dalam jemaa Korintus. Ia melakukan ini karena merasa bertanggung jawab untuk menegakkan kedisiplianan di jemaat tersebut. Paulus merupakan contoh orang percaya yang mau menerapkan pendisiplinan dalam jemaat.

Kedua, pengajaran Paulus tentang menghakimi dalam jemaat tidak bertentangan dengan perjanjian baru pada umumnya yang melarang tentang larangan untuk menghakimi. Pengahakiman dalam jemaat bukan bertujuan untuk menghukum melainkan untuk menjaga kekudusan diri jemaat agar hidup kudus. Jemaat diberi tanggung jawab untuk mengurus diri dengan mengusir orang-orang dalam jemaat yang tidak mau melakukan perintah Allah

Ketiga, perlu jemaat ingat bahwa bukan wewenang mereka untuk menghakimi orang-orang diluar jemaat, karena mereka akan dihakimi oleh Allah sendiri sebagai pemilik penghakiman yang sejati.

Ketiga, pengucilan atau mengusir orang-orang dari dalam jemaat yang sudah tidak mau melakukan Firman Tuhan merupakan hal yang dibenarkan dalam Alkitab. Sekalipun mereka adalah orang yang mengaku diri jemaat, jika gaya hidup jauh dari pada Firman Tuhan maka mereka sebenarnya tidak layak menyandang status orang percaya atau umat Kristus.

\section{Saran-saran}

Pertama, mengingat banyaknya hal yang semakin mendunia dan dianggap biasa saja, sangat berpotensi menjatuhkan jemaat jika tidak pandai dalam menyikapi hal tersebut. Jemaat tidak boleh bermasa bodoh dengan hal-hal yang dibawa oleh perkembangan dunia. 
Termasuk gaya hidup orang-orang masa kini yang dianggap biasa saja, namun bagi gereja hal itu tidak sesuai Firman Tuhan sangat membutuhkan perhatian dari jemaat.

Kedua, dengan adanya skripsi ini, penulis berharap pembaca khususnya orangorang Kristen sadar akan pentingnya menjaga kekudusan dalaam jemaat dan kekudusan pernikahan. Tidak ada gunanya mendiamkan orang-orang dalam jemaat yang melakukan hal tidak baik hanya karena merasa tidak enak atau alasan-alasan tertentu. Semua hal yang mengganggu kekudusan jemaat harus disingkirkan dari dalam jemaat.

Ketiga, mengingat banyaknya keterbatasan penulis dalam menulis skripsi ini, maka tidak mengurangi rasa hormat, penulis mengharapkan masukan dan saran yang bisa membangun dalam memperbaiki tulisan ini. Selain itu, penulis mengharapkan munculnya kajian yang lebih dalam menganai menghakimi dalam jemaat berdasarkan 1 Korintus 5:12-13, agar lebih lagi orang percaya memahami tentang tugas jemaat.

\section{Kepustakaan}

Alkitab. Jakarta: Lembaga Alkitab Indonesia, 2017.

Arichea, Daniel C., dan Howard A. Hatton. Pedoman Penafsiran Alkitab: Surat-surat Paulus kepada Timotius dan kepada Titus. Jakarta: Lembaga Alkitab Indonesia, 2019.

Aritonang, Jan S. Berbagai Aliran di dalam dan di Sekitar Gereja. Jakarta: BPK Gunung Mulia, 1995.

Baker, David L. Roh dan Kebenaran dalam Jemaat: Tafsiran Surat 1 Korintus 12-13. Jakarta: BPK Gunung Mulia, 1991.

Barclay, William. Pemahaman Alkitab Setiap Hari Surat 1\&2 Korintus. Jakarta: BPK Gunung Mulia, 2008.

-. Pemahaman Alkitab Setiap Hari Surat 1\&2 Timotius, Titus, Filemon. Jakarta: BPK Gunung Mulia, 2008.

Bauman, Zygment. Hermeneutic And Social Scince. New York: Calubia Univercity Press, 1978.

Bible Works version 7

Biyanto, Agus, dan Alvin Limengka. Apa Yang Kau Bawa Pulang? 2019. Diakses 16 Juli 2019.

https://books.google.com/books/about/APA_YANG_KAU_BAWA_PULANG.htm 1?hl=id\&id=0JSeDwAAQBAJ.p[o-iio-oiooooioioioioop[o[p-

Blor, Monic de. Semburat Putih Pelangi Kasih. Jakarta: Elex Media Komputindo, 2017.

Bons-storm, M. Apakah Penggembalaan Itu? Jakarta: BPK Gunung Mulia, 1967.

Bratcher, Robert G., dan Eugene A. Nida. Pedoman Penafsiran Alkitab: Surat Paulus

Kepada Jemaat Di Efesus. Lembaga Alkitab Indonesia, 2019.

Brink, H. V. D. Tafsiran Alkitab Kisah Para Rasul. Jakarta: BPK Gunung Mulia, 2008.

Carson, D. A., dan Douglas J. Moo. An Introduction to the New Testament. Malang: Gandum Mas, 2016.

Chapman, Adina. Pengantar Perjanjian Baru. Bandung: Kalam Hidup, 2014.

Chelsia, Anizah dan Robi Panggarra. "Iman Perempuan Kanaan Berdasarkan Kitab Matius

15:21-28." Jurnal Ilmu Teologi dan Pendidikan Agama Kristen 1, no. 2 (Desember 2020): 123-143. http://dx.doi.org/10.25278/jitpk.v1i2.511.

Darmawijaya. Seluk Beluk Kitab Suci. Yogyakarta: Kanisius, 2009. 
Drane, John. Memahami Perjanjian Baru. Jakarta: BPK Gunung Mulia, 2005. https://books.google.com/books/about/Memahami_Perjanjian_Baru.html?hl=id\&id $=\mathrm{U} 8 \mathrm{Sh} 0 \mathrm{gHFm} 8 \mathrm{sC}$.

Duyverman, M. E . Pembimbing Ke Dalam Perjanjian Baru. Jakarta: BPK Gunung Mulia, 2008.

End, Th van den. Ragi Cerita: 1860 - Sekarang. Jakarta: BPK Gunung Mulia, 1999. https://books.google.co.id/books?id=uMn4CaHD1GYC\&pg=PA280\&dq=gereja+k emah+injil+indonesia\&hl=id\&sa=X\&ved=0ahUKEwi3mLGK36XjAhUOU30KHR ByD1EQ6AEIOjAE\#v=onepage \&q=gereja\%20kemah\%20injil\%20indonesia\&f $=\mathrm{fa}$ lse.

Frederik, Hanny. "Prinsip-prinsip Kepemimpinan Penggembalaan Berdasarkan Yohanes 10:1-21 dan Imlementasinya dalam Kepemimpinan Gereja." Jurnal Ilmu Teologi dan Pendidikan Agama Kristen 1, no. 2 (Desember 2020): 69-86. https://ojs.sttjaffray.ac.id/jitpk/article/view/487/pdf_5.

Hadiwardoyo, Purwa. Warisan Paulus Bago Umat. Yogyakarta: Kanisius, t.t. https://books.google.co.id/books?id=scSz_VwsmD8C\&pg=PA10\&dq=warisan+pa ulus+bagi+umat\&hl=id\&sa=X\&ved=0ahUKEwj8nKX7w5PkAhUxjuYKHSbRBy QQ6AEIKTAA\#v=onepage\&q=warisan\%20paulus\%20bagi\%20umat\&f=false

Hadiwijono, Harun. Iman Kristen. Jakarta: BPK Gunung Mulia, 2007.

Harahap, Syahrin. Metodologi Studi Tokoh \& Penulisan Biografi. Jakarta: Prenada Media, 2014.

Hersberger, Anne Krabill. Seksualitas Pemberian Allah. Jakarta: BPK Gunung Mulia, 2006.

Hillyyer, Norman. Tafsiran Alkitab Masa Kini 3 Matius - Wahyu. Jakarta: Yayasan Komunikasi bina Kasih, 2006.

Jonge, Christian de. Apa itu Calvinisme? Jakarta: BPK Gunung Mulia, 1998.

Kamus Besar Bahasa Indonesia, Jakarta: Balai pustaka, 2001.

Kim, Woo Young. Yesuslah Jawaban. Jakarta: BPK Gunung Mulia, 2005.

Kistono, Hari. Paulus Dari Tarsus. Yogyakarta: Kanisius, 2008.

Kristanto, Belly. Ajarlah kami Bertumbuh: Refleksi Atas Surat 1 Korintus. Surabaya: Momentum, 2011.

Luther, Martin. Katekismus Besar Martin Luther. Jakarta: BPK Gunung Mulia, 2007.

Marxsen, Will. Pengantar Perjanjian Baru: Pendekatan Kritis terhadap Masalahmasalahnya. Jakarta: BPK Gunung Mulia, 2008.

Missler, Chuck. Learn the Bible in 24 Hours: Edisi Indonesia. Jakarta: Visimedia, 2006.

Monib, Mohammad, dan Ahmad Nurcholish. Kado Cinta Bagi Pasangan Nikah Beda Agama. Jakarta: Gramedia Pustaka Utama, 2008.

Newman, Barclay M. Kamus Yunani-Indonesia; Untuk Perjanjian Baru. Jakarta: BPK Gunung Mulia, 1991.

OFM, Dianne Bergant, CSA \& Robert J. Karris. Tafsir Alkitab Perjanjian Baru. Yogyakarta: Kanisius, 2010.

Prabowo, Nugroho Sapto, \& Diana Christianti. Terang Hidup: Renungan Harian Dewasa Edisi Tahunan. Gramedia Widiasarana, 2017.

Pfitzner, V. C. Kesatuan Dalam Kepelbagaian: Ulasan atas 1 Korintus. Jakarta: BPK Gunung Mulia, 2006.

https://books.google.com/books/about/Kesatuan_Dalam_Kepelbagaian.html?hl=id \&id=o0xaKe1i80UC. 
Ponto, Rudolof Sripaus. "Skipsi: Kajian Biblika Tentang Kasih yang Semula Berdasarkan Wahyu 2:1-7 dan Implementasinya bagi Orang percaya Masa Kini" Skripsi, S.Th, Sekolah Tinggi Theologia Jaffray, 2015.

Prasetyantha, Y. B. Ekaristi dalam Hidup Kita. Yogyakarta: Kanisius, 2008.

Puspito, Harry. Menyuarakan Kebenaran dan Keadilan Tabloid Reformata Edisi 149 Maret 2012. Jakarta: Yayasan Pelayanan Media Antiokhia, 2012.

Putiray, Friliany. "Studi Etis Kristiani terhadap Pemahaman Pasangan Nikah Married by Accident di Jemaat GPM Galala - Hative Kecil tentang Kekudusan Pernikahan" Skripsi, S. Si-Teol. Universitas Kristen Satya Wacana, 2014. http://repository.uksw.edu/handle/123456789/12258.

Rajo, Gabriel Yobert. "Dosa Yerusalem dalam Yehezkiel 22:1-31: Kajian Biblika dan Implikasi Praktis.” Jurnal Ilmu Teologi dan Pendidikan Agama Kristen 1, no. 2 (Desember 2020): 144-162. https://ojs.sttjaffray.ac.id/jitpk/article/view/518.

Riyadi, Eko. Hidup Dalam Kristus. Yogyakarta: Kanisius, 2008.

SABDA OLB Versi Indonesia

Samarenna, Desti. "Analisis 1 Korintus 14:2-6 Tentang Karunia Berbahasa Roh dan Bernubuat." Dunamis: Jurnal Teologi dan Pendidikan Kristiani 2, no. 1 (4 November 2017): 1-11. https://doi.org/10.30648/dun.v2i1.128.

Sitorus, Jonter Pandapotan. Wawasan Dunia Kristen dan Dunia Ilmu Pengetahuan terhadap Bahasa (Edisi Revisi). Malang, Evernity Fisher Media, 2019.

Sopipater, Karel. Etika Perjanjian Baru. Jakarta: Suara Harapan Bangsa, 2010.

Susanto, Agus. Logos-Tata Bahasa Yunani Koine. Bandung: Bina Madia Informasi, 2011.

Susanta, Yohanes Krismantyo. Harapan di Tengah Penderitaan: Tafsir Atas Daniel 7 dan Hubungannya Dengan Injil Sinoptik. Yogyakarta: Kanisius, 2019.

Sutanto, Hasan. Hermeneutik: Prinsip dan Metode Penafsiran Alkitab. Malang: Seminari Alkitab Asia Tenggara, 1998.

. Perjanjian Baru Interlinear Yunani-Indonesia dan Konkordansi Perjanjian Baru Jilid I. Jakarat: Lembaga Alkitab Indonesia, 2014.

Tenny, Merrill C. Survey Perjanjian Baru. Malang: Gandum Mas, 2013.

Tumanan, Yohanis Luni. "Disiplin Gereja Berdasarkan Injil Matius 18:15-17 Dan Implementasinya Dalam Gereja Masa Kini.” Jurnal Jaffray 15, no. 1 (April 2017): $31-62$.

Vhanhoozer, Kevin J. Is There a Meaning In This Teks? Grand Rapids, Michigan: Zondervan Publishing, 1998.

Wellem, Frederiek Djara. Kamus Sejarah Gereja. Jakarta: BPK Gunung Mulia, 2006.

https://books.google.co.id/books?id=fH7_6rQnCsC\&pg=PA75\&dq=yahudi+diaspora\&hl= id\&sa $=$ X\&ved=0ahUKEwiznLDw-

fDjAhXFdn0KHQtYC8oQ6AEIKTAA\#v=onepage \&q=yahudi\%20diaspora $\& \mathrm{f}=$ fals e.

Wenham, J. W. Bahasa Yunani Koine (The Elements of New Testament Greek). Malang: Seminari Alkitab Asia Tenggara, 1987. 